Research Article

\title{
Generating Behaviors of Strong Tremors and Experimental Study of Rockburst-Triggering Criterion
}

\author{
Guifeng Wang $\mathbb{D}^{1,2}$ Feng Jin $\mathbb{D}^{1},{ }^{1}$ Siyuan Gong $\mathbb{D}^{1},{ }^{1}$ Linming Dou $\mathbb{D}^{1},{ }^{1}$ Chaojun Fan $\mathbb{D}^{2}{ }^{2}$ \\ Wu Cai ${ }^{1}{ }^{1}$ and Xiaoyuan Yuan $\mathbb{D}^{1}$ \\ ${ }^{1}$ State Key Laboratory of Coal Resources and Safe Mining, School of Mines, China University of Mining and Technology, \\ Xuzhou 221116, China \\ ${ }^{2}$ Department of Energy and Mineral Engineering, G3 Center and Energy Institute, The Pennsylvania State University, \\ University Park, State College, PA 16802, USA
}

Correspondence should be addressed to Feng Jin; ts18020014a31@cumt.edu.cn and Siyuan Gong; gsy_cumt@cumt.edu.cn

Received 25 November 2018; Revised 20 March 2019; Accepted 17 April 2019; Published 18 June 2019

Academic Editor: Ivo Caliò

Copyright (c) 2019 Guifeng Wang et al. This is an open access article distributed under the Creative Commons Attribution License, which permits unrestricted use, distribution, and reproduction in any medium, provided the original work is properly cited.

\begin{abstract}
Numerous tremors occur during excavation and mining periods in coal mines, and low-energy tremors often occur before strong tremors. In addition, it is found that not all strong tremors cause rockbursts. Therefore, generating behaviors of strong tremors and the triggering criterion for the occurrence of the rockburst must be investigated. In this study, generating behaviors of strong tremors were inferred by velocity tomograms and energy density clouds. An innovative facility capable of applying dynamic disturbance to roadway models was developed to study the triggering criterion for rockbursts. Velocity tomograms indicated that the stress concentration extended to the syncline region with the advance of the coalface. High-energy-density clouds expanded rapidly and regularly in some areas that were parts of the high-velocity region, indicating that the stress increased rapidly in these areas, until strong tremors took place nearby. AE activities suggested that the modelled roadway offered good resistance as the dynamic loading energy grew from $29.4 \mathrm{~J}$ to $117.6 \mathrm{~J}$. Then, sharp AE activity at the dynamic loading energy of $147 \mathrm{~J}$ indicated the ultimate shock resistance of the roadway was almost reached. Finally, bursting failure of the modelled roadway was observed at a dynamic loading energy of $176.4 \mathrm{~J}$.
\end{abstract}

\section{Introduction}

Rockbursts are the sudden and intense release of elastic energy accumulated in a coal-rock mass during tunnelling and mining. Rockbursts have become a common safety issue in underground coal mining in China. In recent years, more than 170 coal mines in China have suffered rockbursts. The rockburst on 1 March 2011 in the 25110 working face in Yuejin Coal Mine (Yima City, Henan Province, China) damaged a $300 \mathrm{~m}$ long section of the roadway (Figures 1 (a) and 1(a1)). Fifty rockbursts occurred during the mining of the 250204 working face in Yanbei Coal Mine from April 2011 to May 2013. In five months in 2012, four rockbursts occurred in 11-2 working face in Xing'an Coal mine (Heilongjiang Province, China), while eight rockbursts had already occurred in the adjacent working face (Figures 1(b) and 1(b1)). Ten rockbursts took place in Huating Coal Mine (Pingliang City, Gansu Province, China) located in a large fold structure zone from 1 March 2014 to 8 April 2014. On 15 March 2013, a rockburst in Junde Coal Mine, Hegang City (Heilongjiang Province, China), led to the closure of both the tailgate and headgate and trapped 25 miners (Figures 1(c) and 1(c1)). Another rockburst occurred on 15 September 2016, during the tunnelling of the open-off cut in Junde Coal Mine, killing five miners. Previous research demonstrates that rockbursts are likely to be induced in high-stress regions. Recently, with the application of microseismic (MS) monitoring, researchers and mining engineers have gradually reached a consensus whereby high-stress concentration and strong tremors both play an important role in the occurrence of rockbursts [1-3]; that is, when 


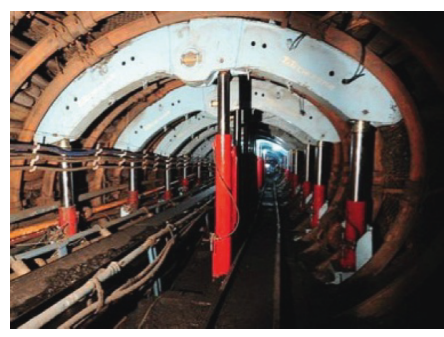

(a)

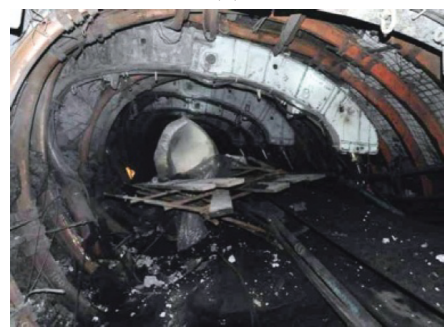

(a1)

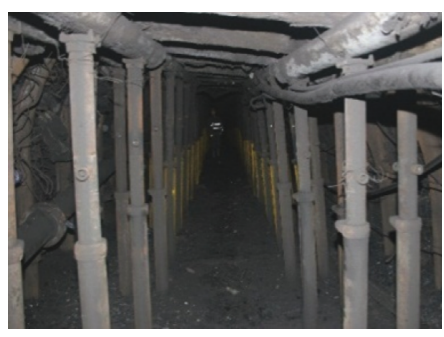

(b)



(b1)

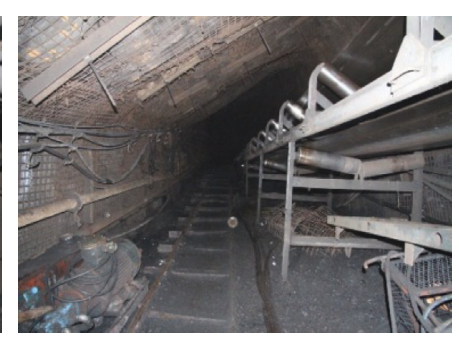

(c)

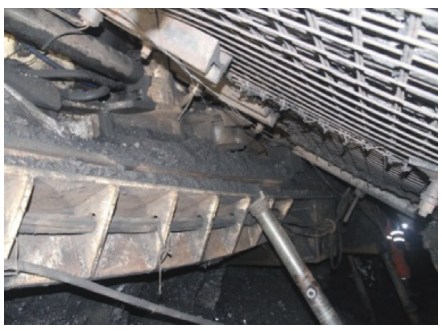

(c1)

Figure 1: Photos in Yuejin (a, a1), Xing'an (b, b1), and Junde (c, c1) coal mines before (upper row) and after (lower row) rockbursts.

roadways with high-stress concentration nearby are disturbed by strong tremors, rockbursts are prone to occur.

During tunnelling and mining periods, there are many mining-induced tremors of different energies and lowenergy tremors often occur before strong tremors. In addition, it is found that not all strong tremors cause rockbursts [4, 5]. Kaiser and Cai [6] found that whether a rockburst was eventually observed or not was closely related to the shock resistance of roadways. Often, obvious shocks can be felt in the roadway at the moment of a strong tremor, but no rockburst ensues. Thus, a proper understanding of generating behaviors of a rockburst from low-energy tremors to the occurrence of strong tremors, and the rockburst-triggering criterion that determines the occurrence of rockbursts can provide useful insights into the evaluation of rockburst hazard as well as revealing their causes. However, diverse geological conditions, mining environments, and changing mining-induced stress make the evolution of microfractures in coal-rock masses extremely complex, bringing the difficulty in precisely identifying the complicated evolution of tremors [4-10]. As the tremor evolution corresponds to the occurrence and development process of microcracks in coal-rock masses, the spatial tremor distribution is extremely complex and evolved in a nonlinear manner over time. Effective means to get the stress and energy characteristics before strong tremors still remain in the exploration and development because of the complexity of the tremor-generating behaviors and the difficulty of precisely identifying the rockburst-triggering criterion in a complicated rock mass fabric. In addition, rockbursts triggered by strong tremors occur in an instant, and it is difficult to study the triggering criterion and failure characteristic of such rockbursts [11-13]. Thus, relevant studies are still in their exploratory or developmental stage.

In this work, roles of strong tremor disturbance and high-stress concentration in the generation of rockbursts were analysed. Two case studies involving strong tremors that triggered the rockburst and did not were studied. Generating behaviors of strong tremores were inferred by energy density clouds and velocity tomograms. Then, an innovative Pendulum Impact Test Facility capable of applying dynamic disturbance to roadway models was developed to study the occurrence of rockbursts to reveal why rockbursts occur. Damage evolution in rock masses surrounding the modelled roadway was monitored by an acoustic emission (AE) system. Acceleration signals and failure processes of the modelled roadway were also recorded. Relevant studies remain both rare and limited. This work involving both studies of generating behaviors of strong tremors and the triggering criterion for rockbursts may provide a new approach to future research on rockburst mechanisms.

\section{Roles of Strong Tremor Disturbance and High-Stress Concentration in Rockbursts}

A rockburst is caused by the abrupt release of elastic energy stored in coal-rock masses. Once a rockburst occurs, coalrock masses surrounding the roadway are immediately driven by the released energy, thus damaging supporting structures and causing casualties (Figure 1). If a significant amount of elastic energy is accumulated in coal-rock masses and then abruptly released, a rockburst will occur. Therefore, an accumulation of sufficient energy is the premise for the occurrence of rockbursts. The energy accumulation is induced by stress concentration. So, when the stress concentration is higher and the stress peak away from excavated boundaries is closer, rockbursts are more likely to occur. Meanwhile, the occurrence of many rockbursts also requires adequate dynamic disturbance that triggers the abrupt release of energy stored in the coal-rock mass. Numerous rockbursts in coal mines are a result of high-stress concentrations combined with dynamic disturbances; that is, a rockburst may occur when the total stress and energy (due to 
the superposition of static stress and dynamic disturbance) within the coal-rock mass reach a certain critical level. The combined effect of static and dynamic stresses was expressed as follows $[3,5,14]$ :

$$
\left\{\begin{array}{l}
\sigma_{\mathrm{s}}+\sigma_{\mathrm{i}}-\sigma_{\mathrm{c}}>0, \\
E_{\mathrm{s}}+E_{\mathrm{i}}-E_{\mathrm{d}}=E_{\mathrm{e}}>0, \quad E_{\mathrm{d}}=\gamma S_{\mathrm{R}},
\end{array}\right.
$$

where $\sigma_{\mathrm{s}}$ and $\sigma_{\mathrm{i}}$ refer to the static stress within the coal-rock masses and the dynamic stress induced by seismic waves, respectively $(\mathrm{MPa}), \sigma_{\mathrm{c}}$ is the critical stress required for a rockburst, $E_{\mathrm{s}}$ is the elastic energy stored in coal-rock masses and induced by the static stress, $E_{\mathrm{i}}$ is the dynamic disturbance energy, $E_{\mathrm{d}}$ is the dissipated energy due to sliding on existing cracks or joints and plastic deformation, $\gamma$ is the dissipated energy required in the unit area, and $E_{\mathrm{e}}$ is the kinetic energy for coal-rock masses moving and flying to roadway. $E_{\mathrm{d}}$ can be defined as $E_{\mathrm{d}}=\gamma S_{\mathrm{R}}$, where $S_{\mathrm{R}}$ is the total failure area.

The dynamic stress generated by the seismic waves can be expressed as follows $[15,16]$ :

$$
\left\{\begin{array}{l}
\sigma_{\mathrm{iP}}=\rho C_{\mathrm{P}} v_{\mathrm{PP}} \\
\sigma_{\mathrm{iS}}=\rho C_{\mathrm{S}} v_{\mathrm{PS}}
\end{array}\right.
$$

where $\sigma_{\mathrm{iP}}$ and $\sigma_{\mathrm{iS}}$ are the normal stress and shear stress induced by the dynamic disturbance, respectively (MPa), $\rho$ is the density of the coal-rock masses $\left(\mathrm{kg} / \mathrm{m}^{3}\right), C_{\mathrm{P}}$ and $C_{\mathrm{S}}$ are the propagation velocities of the $\mathrm{P}$ - and S-waves, respectively $(\mathrm{m} / \mathrm{s})$, and $v_{\mathrm{PP}}$ and $v_{\mathrm{PS}}$ are the particle vibration velocities of the $\mathrm{P}$ - and S-waves, respectively $(\mathrm{m} / \mathrm{s})$.

This is why numerous strong tremors, which will induce dynamic disturbance, happen during mining, while not all strong tremors can trigger rockbursts. For example, as shown in Figure 2(d), a strong rockburst took place in the 11-2 working face in Xing'an Coal Mine (Hegang City, Heilongjiang Province, China) on 15 October 2012 which damaged a roadway section over a length of $104 \mathrm{~m}$. Figure 2 also shows tremors with different energies during mining from 19 September to 15 October 2012. In this period, numerous tremors occurred around the working face, while only one of them triggered a rockburst. Research has shown that the dynamic disturbance caused by seismic waves can be very high, and its influence is usually limited to a certain distance from the source, but the greater the seismic energy, the greater the dynamic stress and further the distance of influence $[17,18]$. As shown in equation (1), the greater the energy released in a tremor, the higher the possibility of a sudden release of energy from a coal-rock mass, leading to the occurrence of rockbursts: thus, it is difficult to study rockburst failures that happen in a sudden, violent manner. Thus, how to study rockburst failures and verify the theory above has attracted much research attention $[1,3]$.

\section{MS Monitoring}

The 11-2 working face in Xing' an Coal Mine had a mining depth of about 600-680 m, with an inclined length of $137 \mathrm{~m}$ and a mining height of $2.6 \mathrm{~m}$. It is located in a large fold structure, and the directions of the two roadways were adjusted twice. Seismic velocity tomography had been used in the detection of stress changes during mining. Mininginduced tremors located by an MS monitoring system offered an easy way in which to conduct seismic velocity tomography. Time-related parameters pertaining to tremors were calculated to generate velocity tomograms using the simultaneous iterative reconstructive technique (SIRT) algorithm [19-22]. Research findings reveal that high-velocity regions are consistent with areas of high-stress concentration, and the locations where strong tremors occur in later mining. Layout of seismic geophones and schematic maps of SOS MS system and seismic velocity tomography were shown in Figure 3. Figure 4 shows the results of seismic velocity tomography at different face-advancing distances. Velocity tomogram (Figure 4(a)) indicates that region A had a high-stress concentration because multiple crossing roadways were located therein. Then, it can be seen from Figures $4(\mathrm{~b})-4(\mathrm{~d})$ that the area and strength of the highvelocity region increased with the advance of the coalface, which indicated that the stress concentration gradually became wider and higher and extended to the syncline region.

Before the rockburst on 15 October, a strong tremor of $1.15 \times 10^{5} \mathrm{~J}$ had already happened in the vicinity of the working face on 26 September, 2012; however, the tremor did not trigger a rockburst. Figure 5(a) shows the spatial distributions of tremors from 19 to 26 September 2012. It can be seen that these tremors gradually showed a relatively concentrated distribution; however, due to the extremely complex spatial characteristics of tremors, it is impossible to intuit the evolutionary law governing tremor activity over time, thus, generating behaviors of the strong tremor could not be inferred from these spatial distribution maps. Thus, a new spatial analysis method with an energy density index for MS monitoring was developed by our research team. The locations, energy, and distances of tremors and time parameter were taken together to describe the evolution of tremors and their spatial distribution. The energy density index of $\rho_{\mathrm{pj}}$ can be expressed as follows $[4,7,23,24]$ :

$$
\rho_{\mathrm{pj}}=\lg \left(\frac{\sum_{t_{i} \in P} \sqrt{E_{t_{i}}}}{S_{j}}\right),
$$

where $\rho_{\mathrm{pj}}$ refers to the index of energy density $\left(\lg \left(\sqrt{\mathrm{J}} / \mathrm{m}^{2}\right)\right)$, $E_{t_{i}}$ represents the energy of tremors in the statistical grid cell $(\mathrm{J}), P$ denotes the statistical time (d), and $S_{j}$ represents the area of the statistical region $\left(\mathrm{m}^{2}\right)$.

Figure 5(b) shows energy density clouds of tremors obtained by using the calculation method with the index of energy density shown in equation (3): energy density clouds began to appear in local region $B$ of the working face on 19 September 2012. Then, region B became the core for the expansion of the energy density clouds. From 20 to 25 September 2012, the expansion of the energy density clouds surrounding region $\mathrm{B}$ accelerated, leading to increases in the area and strength of the high-energy-density regions. Energy density clouds were located in the syncline region with highstress concentration as inferred by velocity tomograms 


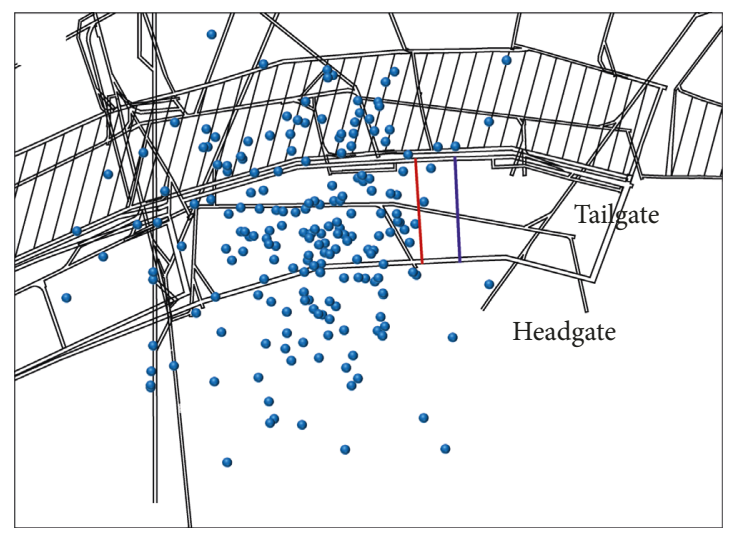

- Advancing line on 19 September 2012

- Advancing line on 15 October 2012 that is the day of a rockburst $10^{2} \sim 9.9 \times 10^{2} \mathrm{~J}$

(a)

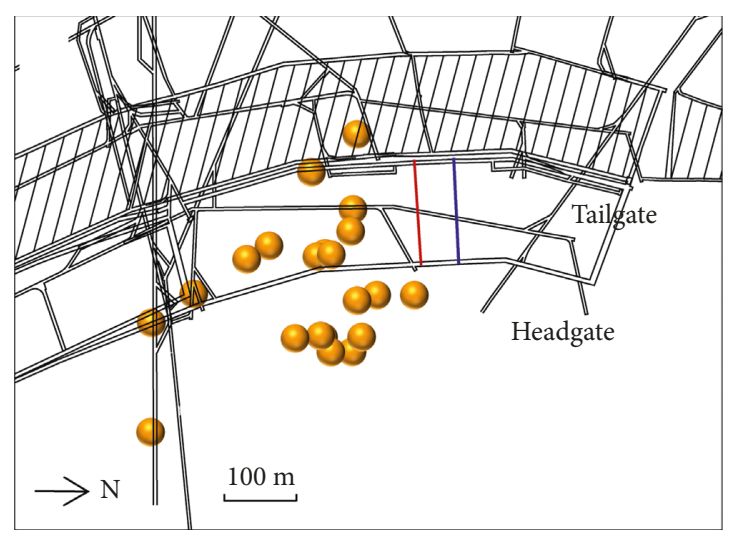

_- Advancing line on 19 September 2012

- Advancing line on 15 October 2012 that is the day of a rockburst $10^{4} \sim 9.9 \times 10^{4} \mathrm{~J}$

(c)

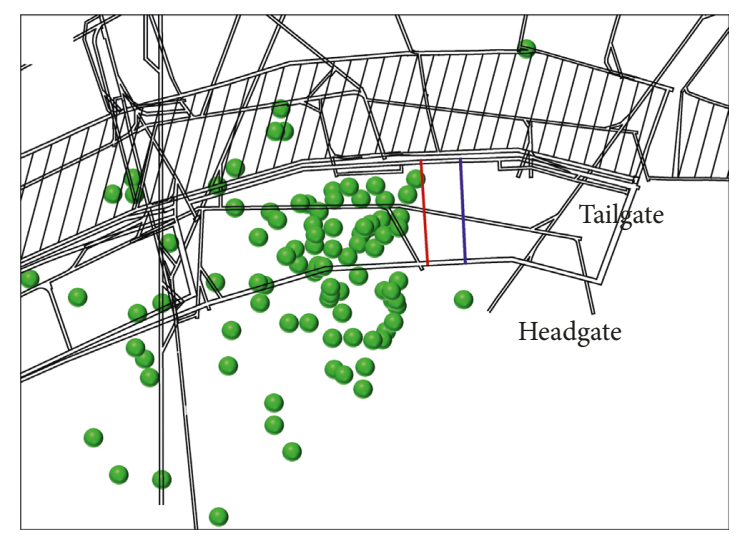
- Advancing line on 19 September 2012
- Advancing line on 15 October 2012 that is the day of a rockburst
$10^{3} \sim 9.9 \times 10^{3} \mathrm{~J}$

(b)

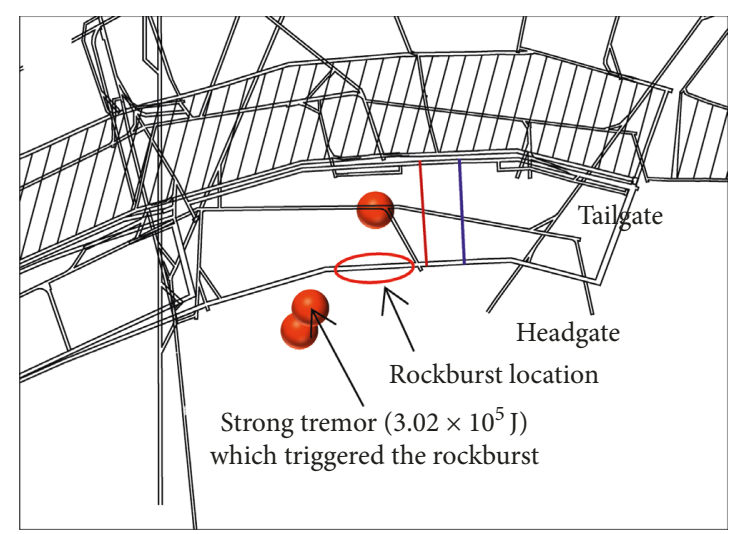
- Advancing line on 19 September 2012
_- Advancing line on 15 October 2012 that is the day of a rockburst $\geq 10^{5} \mathrm{~J}$

(d)

Figure 2: Tremors with different energies occurring during mining from 19 September to 15 October 2012.



(a)

Figure 3: Continued. 

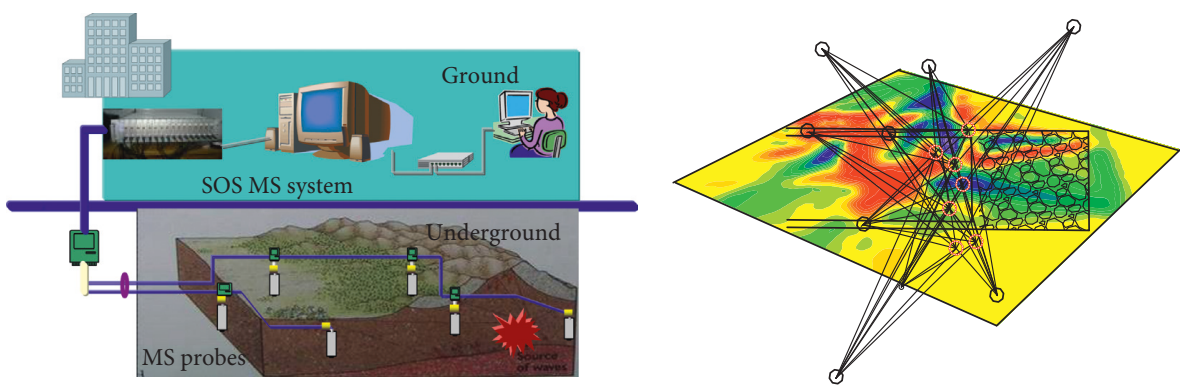

O Mining-induced tremors

O MS probes

(b)

(c)

FIGURE 3: Layout of seismic geophones (a) and schematic maps of SOS MS system (b) and seismic velocity tomography (c).

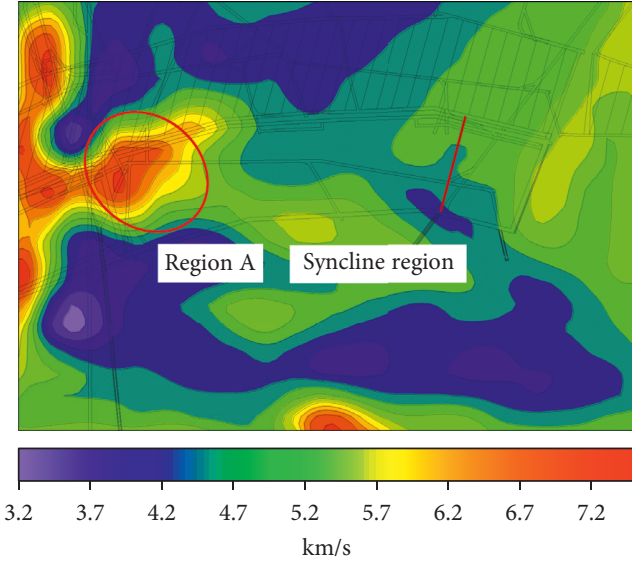

__ Advancing line

(a)

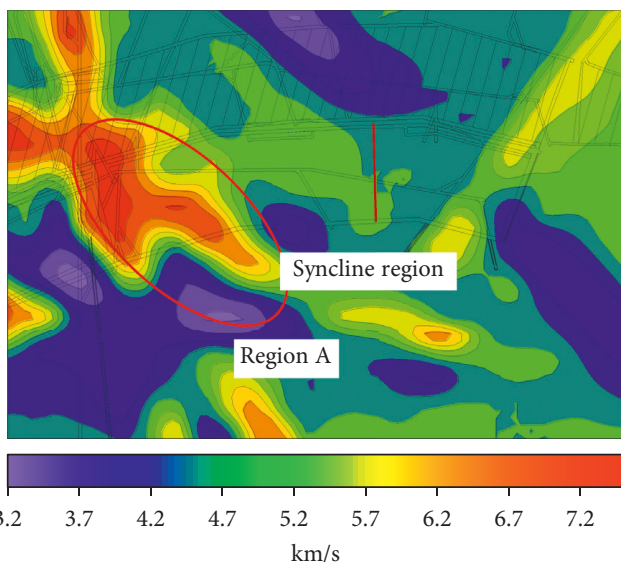

__ Advancing line

(c)

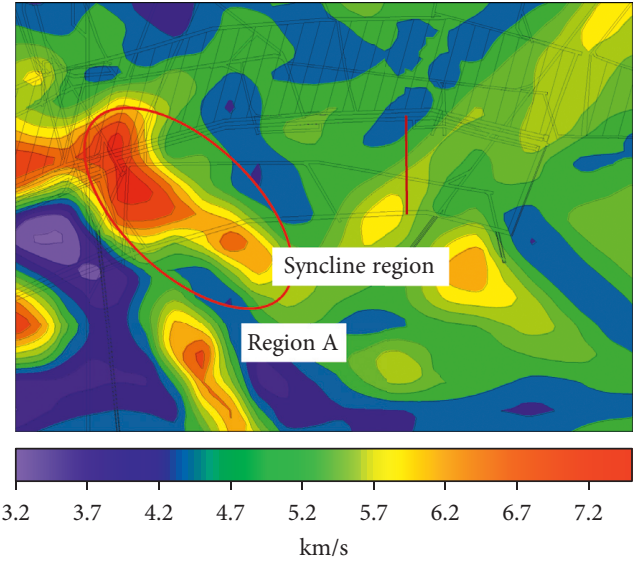

__ Advancing line

(b)



(d)

FIGURE 4: Seismic velocity tomography results at different advancing distances during mining.

(Figure 3(c)). On 26 September 2012, a strong tremor of $1.15 \times 10^{5} \mathrm{~J}$ took place in the vicinity of the energy density clouds, while only obvious shocks were felt in the roadways and no rockburst occurred.
After the occurrence of the strong tremor on 26 September 2012, a quiescent period ensued, as shown in Figure 6, and then nuclei of energy density clouds appeared in region $\mathrm{C}$ of the working face on 8 October 2012. From 9 

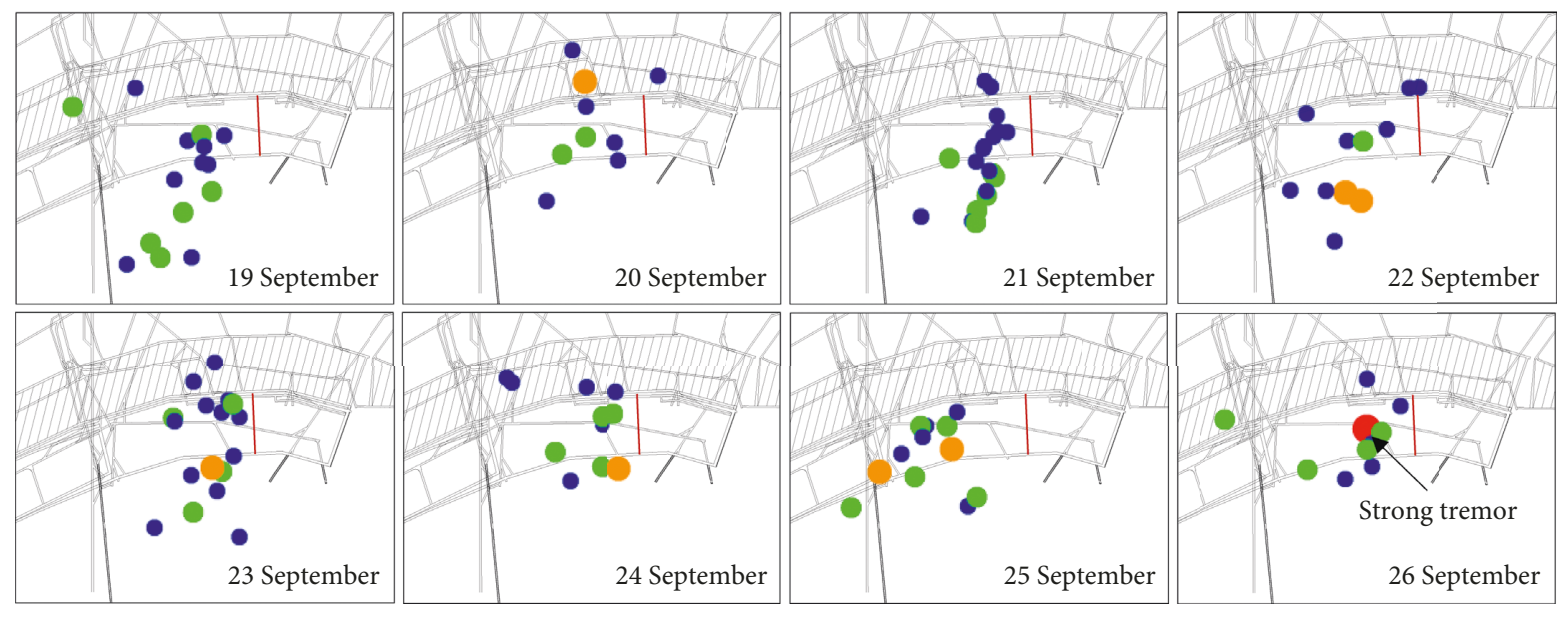

$$
\begin{aligned}
& \text { Advancing line } \\
& 10^{2} \sim 9.9 \times 10^{2} \mathrm{~J} \\
& 10^{3} \sim 9.9 \times 10^{3} \mathrm{~J}
\end{aligned}
$$

$$
\begin{aligned}
& 10^{4} \sim 9.9 \times 10^{4} \mathrm{~J} \\
& \geq 10^{5} \mathrm{~J}
\end{aligned}
$$

(a)



(b)

FiguRE 5: Evolution of spatial tremors (a) and energy density clouds (b) before a strong tremor (19-26 September 2012).

to 13 October 2012, the energy density clouds expanded rapidly around region $\mathrm{C}$, with growing strength. On 14 October 2012, a large area of high-strength energy density cloud formed at the syncline structure. As displayed in Figure $6(\mathrm{~h})$, a strong tremor of $1.29 \times 10^{5} \mathrm{~J}$ occurred in region $\mathrm{C}$ at first, while it did not trigger a rockburst. Then, it was followed by another strong tremor of $3.02 \times 10^{5} \mathrm{~J}$, which induced a strong rockburst. In comparison with Figure 6, the strength of the energy density clouds increased greatly before the occurrence of the rockburst, which indicated that region $\mathrm{C}$ might be subject to a higher stress concentration, and the second strong tremor released more energy than the first; therefore, equation (1) was satisfied with the superposition of static stress and dynamic disturbance. Thus, a rockburst occurred.
As shown in Figure 4, velocity tomograms showed that there was a large-scale region with high-stress concentration in front of the coalface. High-energy-density clouds expanded rapidly and regularly in some local areas that were parts of the high-velocity region, indicating further stress increases in these areas, until strong tremors occurred nearby. The evolution of energy density clouds was the response to the rising stress (static stress) in some local areas before the rockburst. With the increase of the static stress, numerous tremors with small energy appeared first, and then strong tremors occurred. Thus, the nucleation and strengthening of energy density clouds could be used as the precursor of strong tremors. When a strong tremor occurred, it generated strong seismic waves and dynamic stress. The rockburst occurred once the stress and energy 


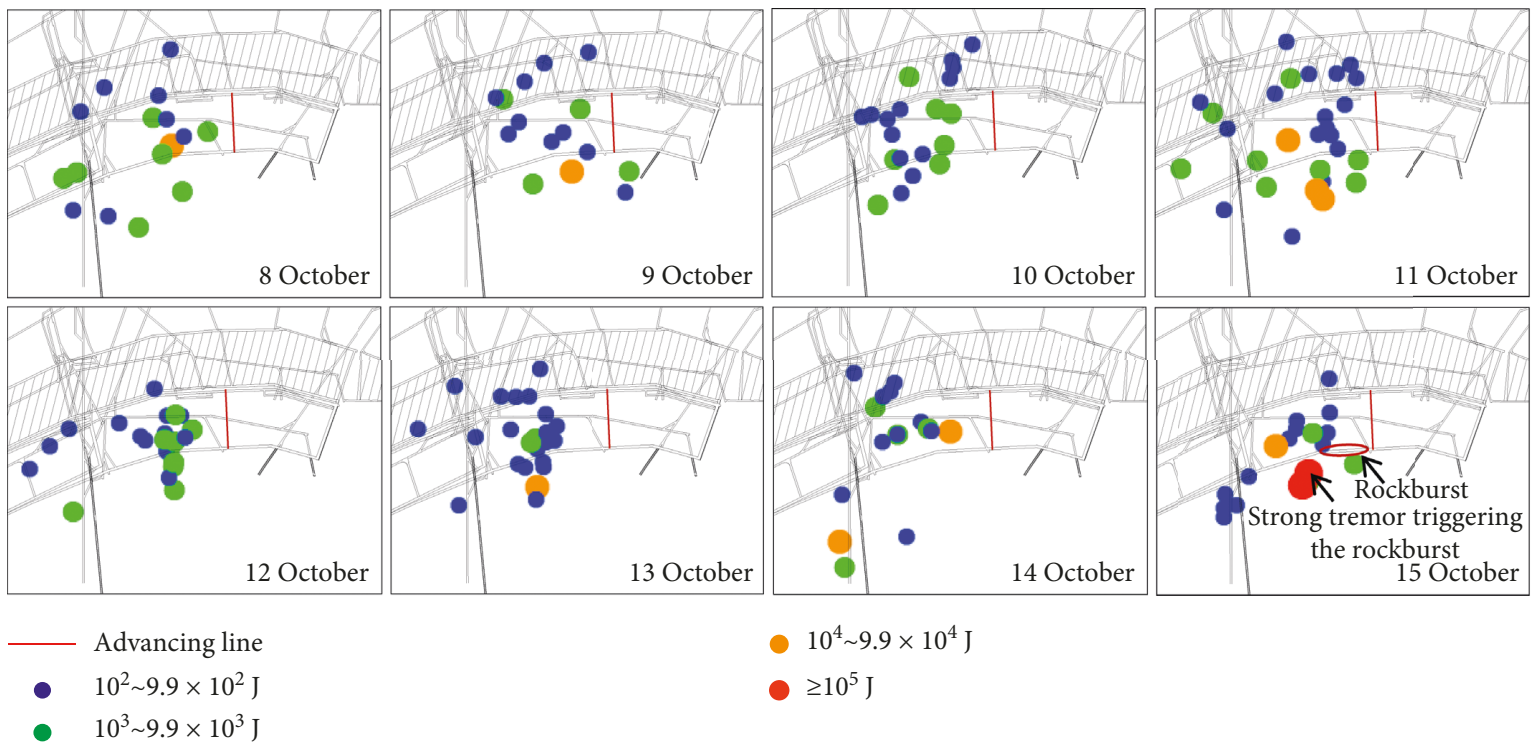

(a)

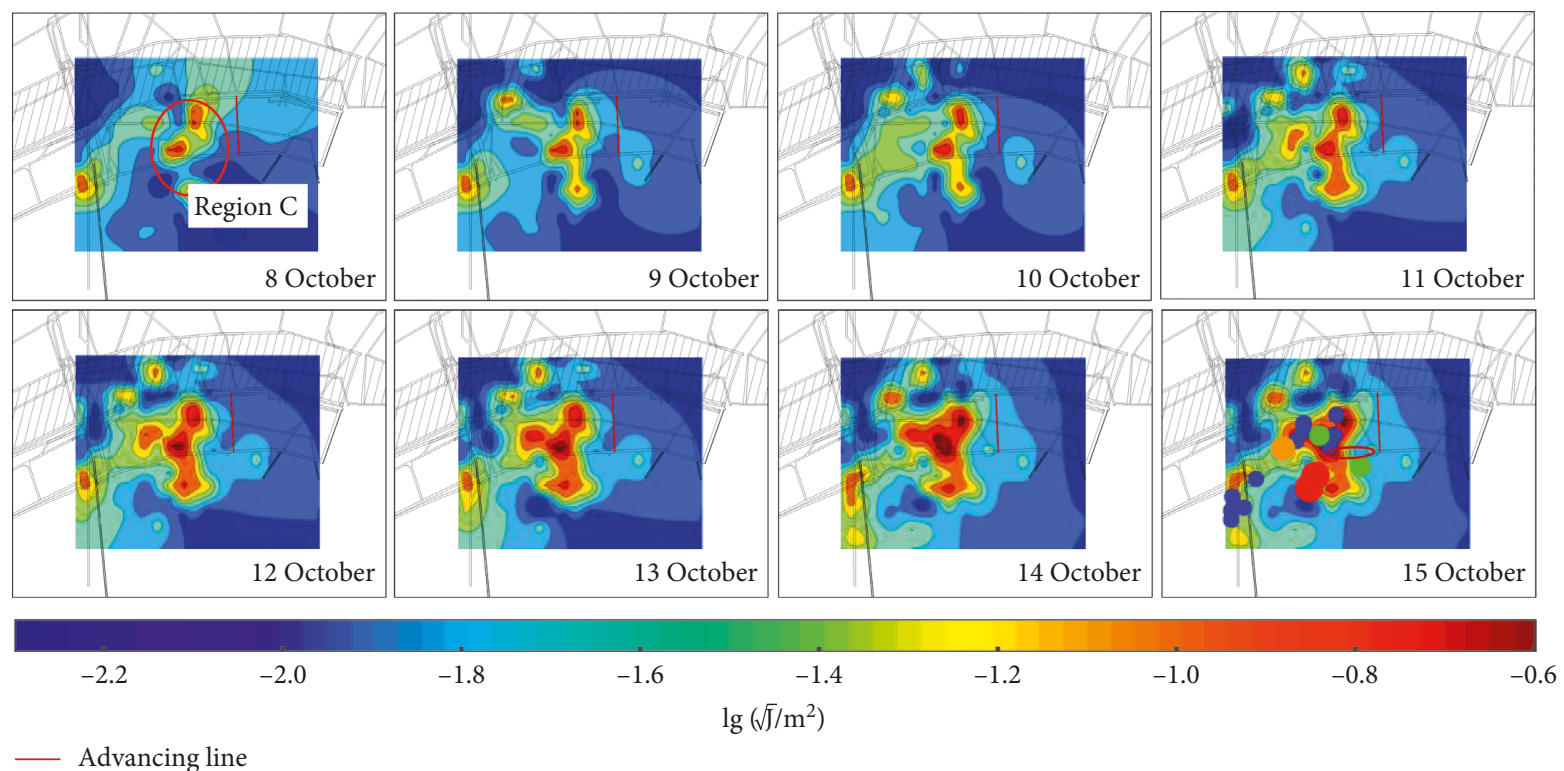

(b)

FIgURE 6: Evolution of spatial tremors (a) and energy density clouds (b) before a rockburst (8-15 October 2012).

generated by the combination of static and dynamic stresses exceeded the limits in some local areas. Energy density clouds and seismic velocity tomographs can indicate the stress and energy concentration and provide a new approach to assess the static stress during the generating process of a rockburst. Meanwhile, as shown in the equation (2), the higher the released energy of tremors, the higher the dynamic stress will be induced, then the higher the probability that the rockburst occurs. In order to reveal the effect of dynamic stress before a rockburst, laboratory tests had been done with dynamic disturbance applying to roadway models in Section 4.

Note that a rockburst is more likely to occur in areas with high-stress concentration. Conversely, they do not occur readily in areas of low stress concentration because strong tremors with high seismic energies are needed in such circumstances and such events are rare; for examples, in some areas at a working face where there are folds and coal pillars, coal-rock masses are likely to store significant elastic energy after the mining-induced stress is superimposed on the tectonic stress or the stress imposed by coal pillars $[22,25,26]$. When the coalface is advanced to these regions that had high-stress concentrations, rockbursts are prone to occur therein. As shown in Figures 4-6, the high-stress feature in seismic velocity tomographs appeared earlier than the emergence of energy density clouds, which indicated the occurrence of tremors was the response to the further rising stress concentration. 


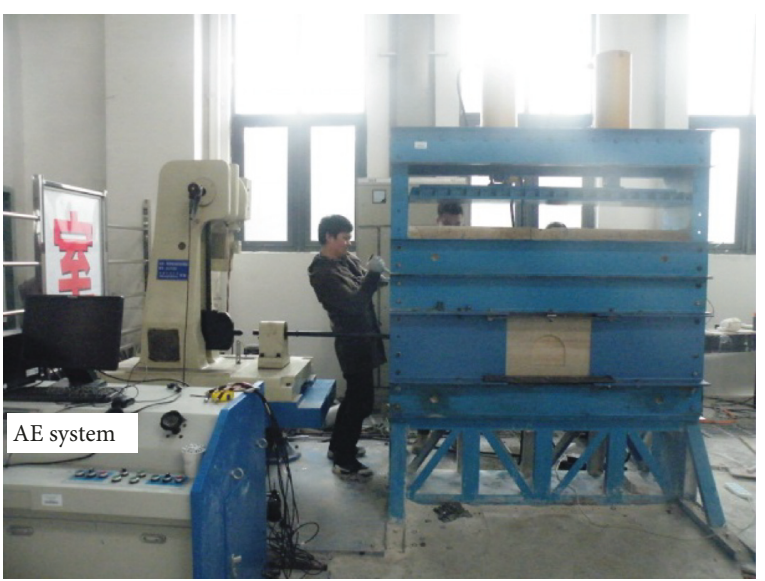

(a)

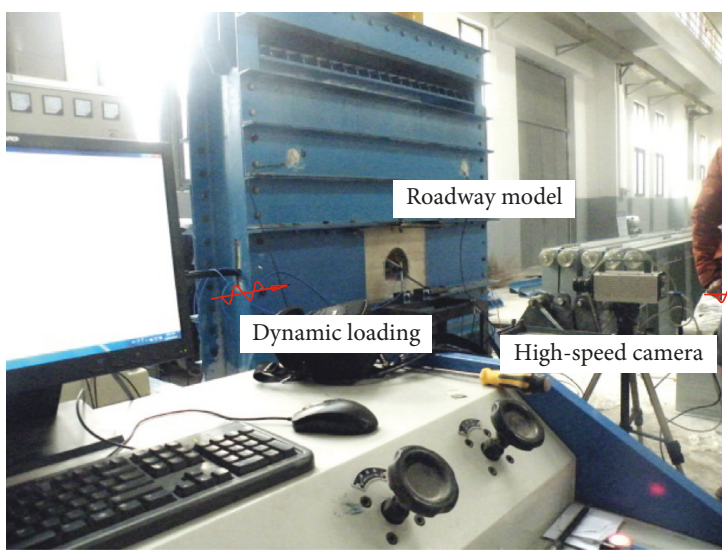

(c)

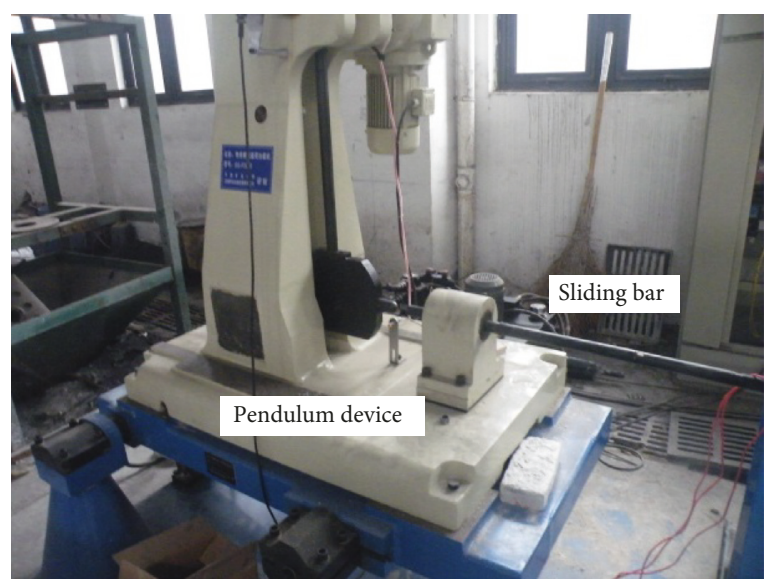

(b)

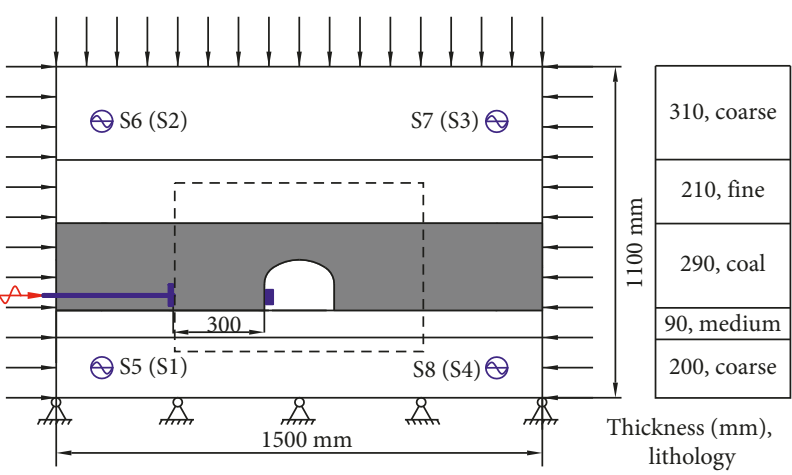

(2) Acoustic emission sensors

$\bar{I}_{-}$F Focus region of the roadway structure

- Acceleration sensors

(d)

Figure 7: Test facility (a); pendulum device (b); test photograph (c); test schematic diagram (d).

\section{Model Testing}

4.1. Methods. From the above analysis, it can be seen that when static stress and dynamic disturbance are superimposed, the total stress and energy can readily surpass their critical values, whereupon a rockburst may occur. The critical stress and energy required for a rockburst may vary with various factors including the coal-rock properties, stress state, loading rate, and supporting schemes. However, it is difficult to measure such parameters in the field. Laboratory tests or numerical simulation are effective means with which to study the occurrence of rockbursts and are conducive to revealing causes of rockburst. A novel Pendulum Impact Test Facility was developed to study the occurrence of rockbursts triggered by dynamic disturbance (Figure 7). A sleeve containing a sliding bar was buried in the model. By releasing the pendulum to strike this bar, a dynamic energy input was generated to simulate the abrupt energy release of a point seismic source in coal-rock masses near a roadway. Above the model, a hydraulic cylinder was set up to apply vertical stress, while horizontal stress on the two sides of the model was applied by oil packets. The similarity ratios of geometry, density, force, and energy are $C_{l}=17.39, C \rho=1.47, C=25.57$, and $C_{E}=1.34 \times 10^{5}$, respectively, according to similarity theory $[17,27,28]$. The modelled roadway, with an axial length of $400 \mathrm{~mm}$, simulated an arched underground cavern with a bottom width of $4.0 \mathrm{~m}$ and a centreline height of $3.0 \mathrm{~m}$. The physical and mechanical properties of the real and modelled rocks are listed in Table 1. According to field survey data and the requisite force scale, a vertical stress of $0.59 \mathrm{MPa}$ and a horizontal stress of $0.86 \mathrm{MPa}$ were applied to the model before excavation. After the tunnel was excavated, the vertical stress was increased to $1.18 \mathrm{MPa}$ to simulate the influence of mining stress.

In the test, the pendulum (mass, $20 \mathrm{~kg}$ ) was elevated from $150 \mathrm{~mm}$ to $900 \mathrm{~mm}$ in increments of $150 \mathrm{~mm}$ : the corresponding dynamic loading energies were $29.4 \mathrm{~J}, 58.8 \mathrm{~J}$, $88.2 \mathrm{~J}, 117.6 \mathrm{~J}, 147 \mathrm{~J}$, and $176.4 \mathrm{~J}$, respectively. In this way, the successively growing tremor energy was simulated. The tremor energy measured in coal mines was basically $0.26 \%$ to $3.6 \%$ of the total energy released in the rupture of the coal-rock masses $[17,18]$. The absorption efficiency of the dynamic energy input generated by the pendulum was assumed to be $85 \%$ [29]. Based on this, it was calculated that the simulated maximum tremor energy was $0.52 \times 10^{5} \mathrm{~J}$ to $7.23 \times 10^{5} \mathrm{~J}[17,27]$, which was equivalent to the energy magnitude of strong tremors recorded in the field. An 
TABLE 1: Mechanical and material properties of rocks.

\begin{tabular}{|c|c|c|c|c|c|c|c|c|}
\hline \multirow[b]{2}{*}{ Lithology } & \multicolumn{3}{|c|}{ Natural rock properties } & \multicolumn{2}{|c|}{ Model materials and ratios } & \multicolumn{3}{|c|}{ Modelled rock properties } \\
\hline & $\begin{array}{c}\text { Unit } \\
\text { weight } \\
\left(\mathrm{kN} / \mathrm{m}^{3}\right)\end{array}$ & $\begin{array}{c}\text { Compressive } \\
\text { strength } \\
(\mathrm{MPa})\end{array}$ & $\begin{array}{c}\text { Young's } \\
\text { modulus } \\
(\mathrm{GPa})\end{array}$ & $\begin{array}{l}\text { Ratio of sand } \\
\text { and binder }\end{array}$ & $\begin{array}{l}\text { Ratio of cement } \\
\text { and gypsum }\end{array}$ & $\begin{array}{c}\text { Unit } \\
\text { weight } \\
\left(\mathrm{kN} / \mathrm{m}^{3}\right)\end{array}$ & $\begin{array}{c}\text { Compressive } \\
\text { strength } \\
(\mathrm{MPa})\end{array}$ & $\begin{array}{c}\text { Young's } \\
\text { modulus } \\
(\mathrm{GPa})\end{array}$ \\
\hline Coarse sandstone & 25.2 & 81.67 & 31.39 & $4: 1$ & $7: 3$ & 20.629 & 2.945 & 0.72 \\
\hline Fine sandstone & 24.8 & 59.75 & 26.51 & $5: 1$ & $7: 3$ & 18.2182 & 2.398 & 0.45 \\
\hline Coal seam & 13.2 & 17.92 & 9.80 & $8: 1$ & $5: 5$ & 17.1794 & 0.821 & 0.29 \\
\hline $\begin{array}{l}\text { Medium } \\
\text { sandstone }\end{array}$ & 24.5 & 71.28 & 29.88 & $4: 1$ & $5: 5$ & 18.3946 & 2.783 & 0.61 \\
\hline
\end{tabular}

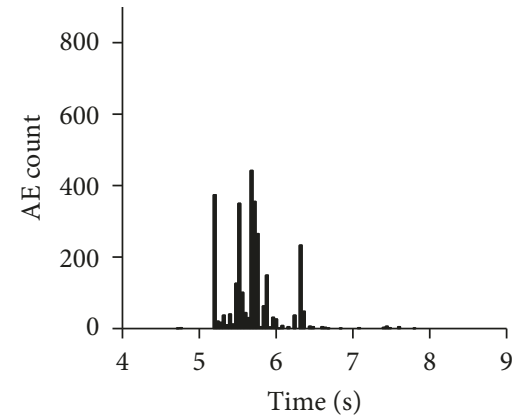

(a)

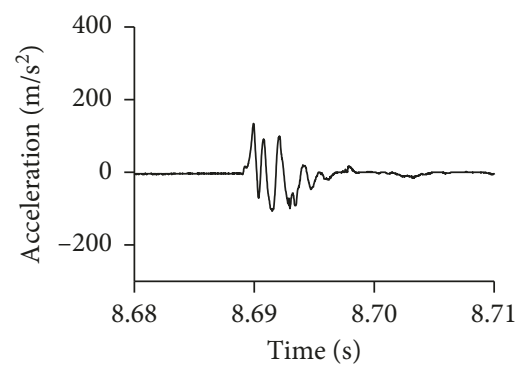

(a1)

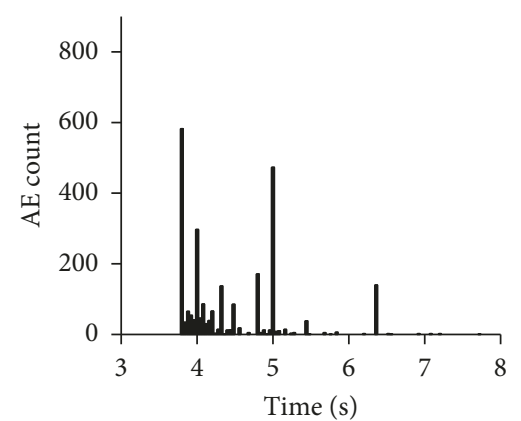

(d)

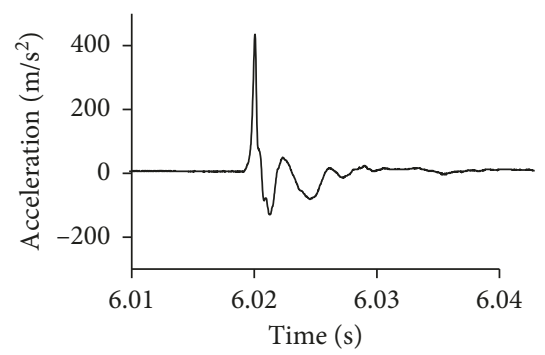

(d1)

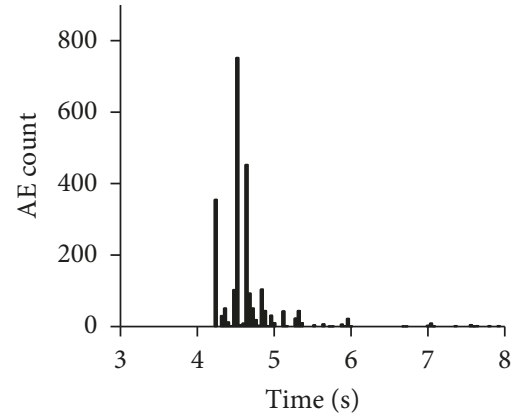

(b)

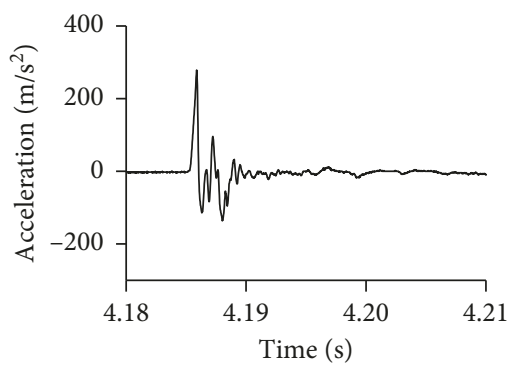

(b1)

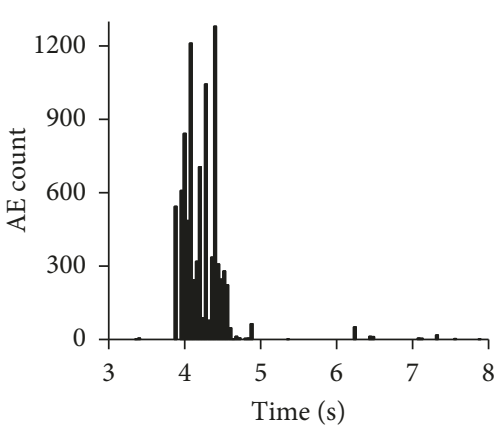

(e)

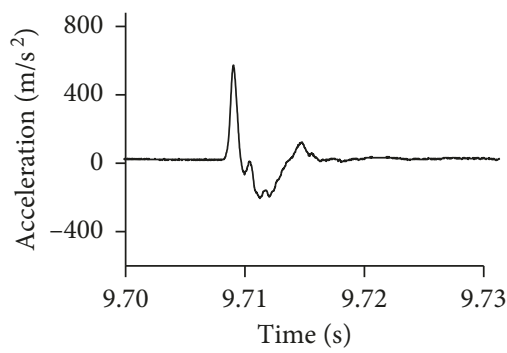

(e1)

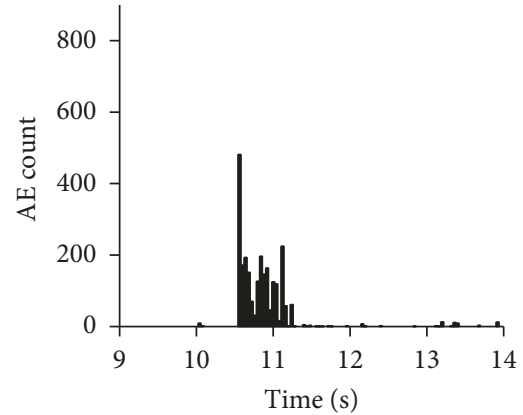

(c)

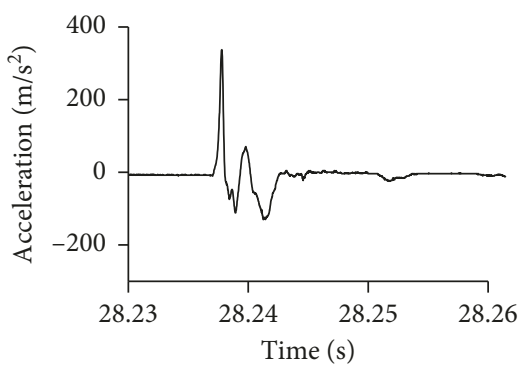

(c1)

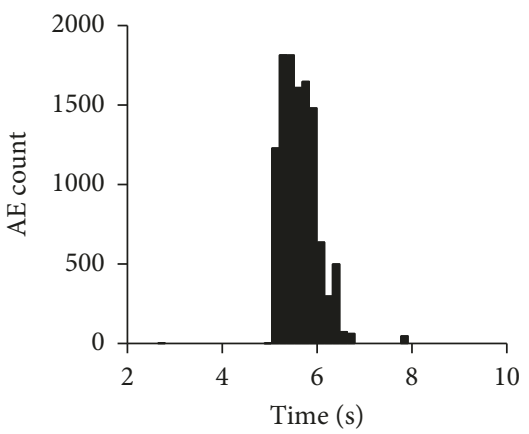

(f)

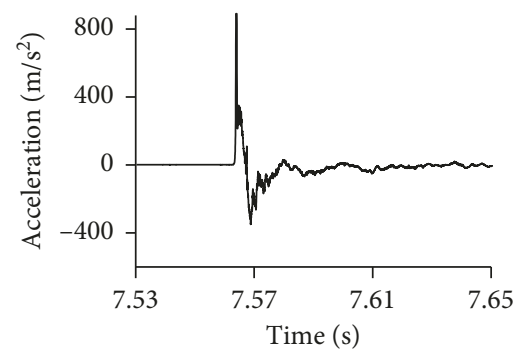

(f1)

FIGURE 8: AE activity and acceleration signals at different input energies: (a, a1) $29.4 \mathrm{~J}$; (b, b1) $58.8 \mathrm{~J}$; (c, c1) 88.2 J; (d, d1) $117.6 \mathrm{~J}$; (e, e1) 147 J; (f, f1) $176.4 \mathrm{~J}$. 




FIgURE 9: Cumulative AE counts and acceleration peaks at different input energies.

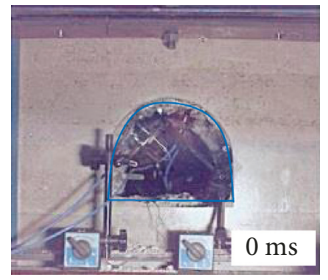

(a)

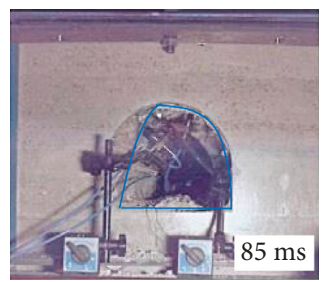

(f)

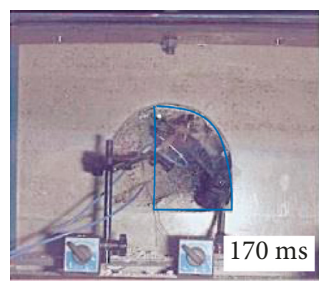

$(\mathrm{k})$

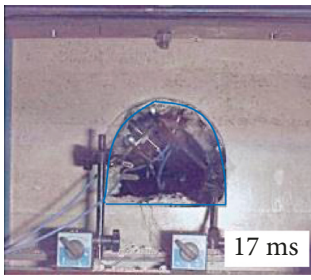

(b)

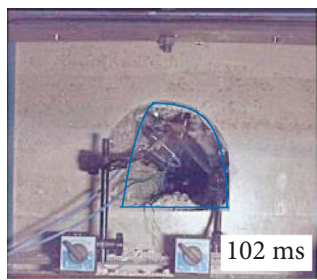

(g)

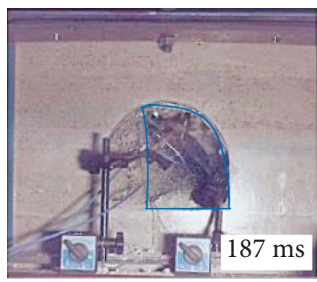

(l)

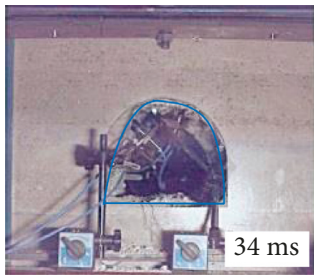

(c)

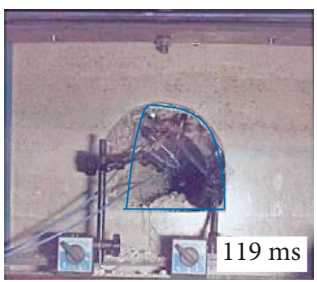

(h)

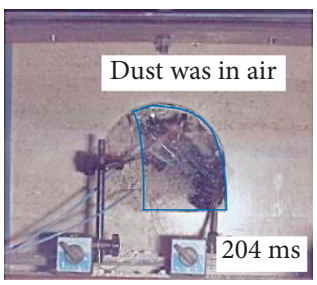

(m)

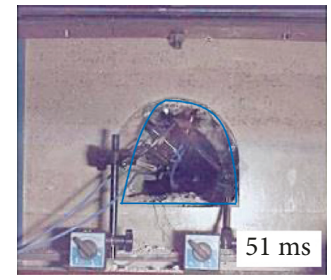

(d)

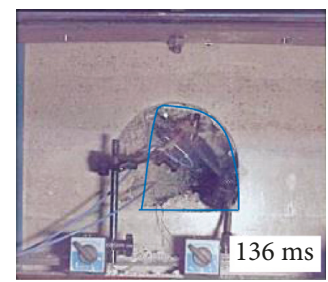

(i)

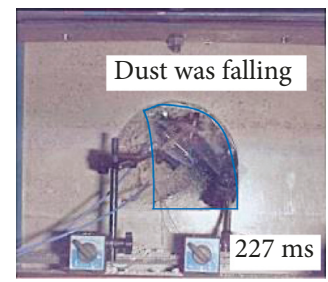

(n)

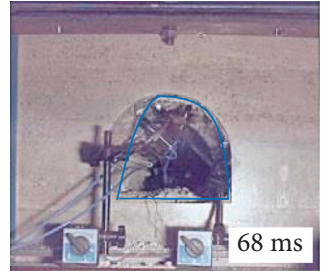

(e)

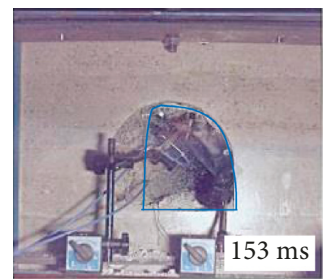

(j)

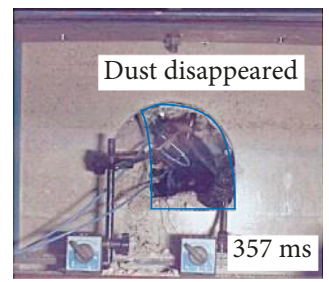

(o)

FIgURE 10: Rockburst failure of the modelled roadway recorded by a high-speed camera.

acoustic emission (AE) system was adopted to monitor the internal damage in rocks surrounding the roadway after each dynamic energy input. An ultradynamic signal testing system (DH5960) with an acquisition rate of $50 \mathrm{kHz}$ was used to measure acceleration signals in the modelled roadway. A high-speed camera was used to track the instantaneous failure process.

4.2. Results of Laboratory Tests and Their Analysis. Figure 8 shows the characteristics of AE activity and acceleration signals when the input energy was increased.
As shown in Figure 9, AE activities did not exhibit significant changes as the input energy was increased from $29.4 \mathrm{~J}$ to $117.6 \mathrm{~J}$. This suggested that the roadway retained good resistance to dynamic loading at that time. Meanwhile, acceleration peaks gradually increased with increased input energy. When the input energy increased to $147 \mathrm{~J}$, the roadway remained stable, but the AC count increased, which indicated that significant damage had been sustained within the rocks surrounding the roadway, and in that case, the roadway almost reached its ultimate shock resistance. As the input energy increased to $176.4 \mathrm{~J}$, the roadway underwent a rockburst, the instantaneous 
failure process of which is demonstrated in Figure 10. The results revealed that the sudden energy release from rocks surrounding the roadway can only be triggered when the tremor energy reached a certain value, thus a rockburst occurred.

Under certain geological and stress conditions, the limiting tremor energy of a roadway structure is fixed, while roadway structures under different geological and stress conditions could bear different intensities of tremor [30, 31]. For example, in 492 rockbursts in Yima Coalfield (Yima City, Henan Province, China), most roadways underwent rockbursts when the tremor energy reached $1 \times 10^{5} \mathrm{~J}$. Few roadways could bear a higher magnitude tremor. While, in 83 rockbursts in Huating Coalfield (Pingliang City, Gansu Province, China), most roadways suffered rockbursts when the tremor energy reached $1 \times 10^{6} \mathrm{~J}$. The frequency and energy of tremors both significantly increase with increasing mining depth $[2,3,32,33]$. This has resulted in numerous rockbursts being triggered in recent years. For example, before 1950, only two coal mines in China were reported to have suffered rockbursts, and the number increased to 8,14 , and 30 in the 1950s, 1960s, and 1970s, respectively, while there are now more than 170 coal mines in China suffering rockbursts.

\section{Conclusions}

The research involved both generating behaviors of strong tremors and the triggering criterion for the rockburst. The following conclusions were obtained:

(1) The high-stress feature in seismic velocity tomographs appeared earlier than the emergence of energy density clouds. Energy density clouds exhibited obvious nucleation characteristics and expanded rapidly and regularly in some local areas that were parts of the high-velocity region, until strong tremors occurred nearby.

(2) AE activities suggested that the modelled roadway still had significant shock resistance before the dynamic load reaches a certain value. After that, a jump in the $\mathrm{AE}$ count at an applied dynamic loading energy indicated the ultimate shock resistance of the roadway was almost reached. The sudden energy release from rocks surrounding the roadway can only be triggered when the tremor energy reached a certain value.

\section{Data Availability}

The calculation data used to upport the findings of this study are available from the corresponding author upon request.

\section{Conflicts of Interest}

The authors declare that they have no conflicts of interest.

\section{Acknowledgments}

This work was supported by the Fundamental Research Funds for the Central Universities (grant number
2017QNA27) and the Academic Programme for Development of Jiangsu Higher Education Institutions in China (grant number SZBF2011-6-B35).

\section{References}

[1] L. Hu, K. Ma, X. Liang, C. Tang, Z. Wang, and L. Yan, "Experimental and numerical study on rock burst triggered by tangential weak cyclic dynamic disturbance under true triaxial conditions," Tunnelling and Underground Space Technology, vol. 81, pp. 602-618, 2018.

[2] W. D. Ortlepp, "The behaviour of tunnels at great depth under large static and dynamic pressures," Tunnelling and Underground Space Technology, vol. 16, no. 1, pp. 41-48, 2001.

[3] C. Zhang, I. Canbulat, B. Hebblewhite, and C. R. Ward, "Assessing coal burst phenomena in mining and insights into directions for future research," International Journal of Coal Geology, vol. 179, pp. 28-44, 2017.

[4] W. Cai, L. Dou, M. Zhang, W. Cao, J.-Q. Shi, and L. Feng, "A fuzzy comprehensive evaluation methodology for rock burst forecasting using microseismic monitoring," Tunnelling and Underground Space Technology, vol. 80, pp. 232-245, 2018a.

[5] L.-M. Dou, Z.-L. Mu, Z.-L. Li, A.-Y. Cao, and S.-Y. Gong, "Research progress of monitoring, forecasting, and prevention of rock burst in underground coal mining in China," International Journal of Coal Science \& Technology, vol. 1, no. 3, pp. 278-288, 2014.

[6] P. K. Kaiser and M. Cai, "Design of rock support system under rock burst condition," Journal of Rock Mechanics and Geotechnical Engineering, vol. 4, no. 3, pp. 215-227, 2012.

[7] A. Frankel, "Mapping seismic hazard in the central and eastern United States," Seismological Research Letters, vol. 66, no. 4, pp. 8-21, 1995.

[8] T.-H. Ma, C.-A. Tang, S.-B. Tang et al., "Rock burst mechanism and prediction based on microseismic monitoring," International Journal of Rock Mechanics and Mining Sciences, vol. 110, pp. 177-188, 2018.

[9] B. Orlecka-Sikora, S. Lasocki, G. Lizurek, and Ł. Rudziński, "Response of seismic activity in mines to the stress changes due to mining induced strong seismic events," International Journal of Rock Mechanics and Mining Sciences, vol. 53, no. 9, pp. 151-158, 2012.

[10] C. A. Tang, J. Wang, and J. Zhang, "Preliminary engineering application of microseismic monitoring technique to rock burst prediction in tunneling of Jinping II project," Journal of Rock Mechanics and Geotechnical Engineering, vol. 2, no. 3, pp. 193-208, 2010.

[11] W. D. Ortlepp and T. R. Stacey, "Rock burst mechanisms in tunnels and shafts," Tunnelling and Underground Space Technology, vol. 9, no. 1, pp. 59-65, 1994.

[12] S. Prusek and W. Masny, "Analysis of damage to underground workings and their supports caused by dynamic phenomena," Journal of Mining Science, vol. 51, no. 1, pp. 63-72, 2015.

[13] A. Zubelewicz and Z. Mróz, "Numerical simulation of rock burst processes treated as problems of dynamic instability," Rock Mechanics and Rock Engineering, vol. 16, no. 4, pp. 253-274, 1983.

[14] X. Li, F. Gong, M. Tao et al., "Failure mechanism and coupled static-dynamic loading theory in deep hard rock mining: a review," Journal of Rock Mechanics and Geotechnical Engineering, vol. 9, no. 4, pp. 767-782, 2017.

[15] J. He, L. Dou, S. Gong, J. Li, and Z. Ma, "Rock burst assessment and prediction by dynamic and static stress analysis 
based on micro-seismic monitoring," International Journal of Rock Mechanics and Mining Sciences, vol. 93, pp. 46-53, 2017.

[16] Z. Wang, L. Dou, and G. Wang, "Coal burst induced by horizontal section mining of a steeply inclined, extra-thick coal seam and its prevention: a case study from Yaojie No. 3 Coal Mine, China," Shock and Vibration, vol. 2019, Article ID 8469019, 13 pages, 2019.

[17] W. Cai, Fault rock burst induced by static and dynamic loads superposition and its monitoring and warning, Ph.D. thesis, China University of Mining and Technology, Xuzhou, China, 2015.

[18] H. He, L. Dou, A. Cao, J. Fan, and Y. L. Ding, "Mechanisms of mining seismicity under large scale exploitation with multikey strata," Shock and Vibration, vol. 2015, Article ID 121053, 8 pages, 2015.

[19] W. Cai, L. Dou, S. Gong, Z. Li, and S. Yuan, "Quantitative analysis of seismic velocity tomography in rock burst hazard assessment," Natural Hazards, vol. 75, no. 3, pp. 2453-2465, 2015.

[20] M. J. Friedel, D. F. Scott, M. J. Jackson, T. J. Williams, and S. M. Killen, "3-D tomographic imaging of anomalous stress conditions in a deep US gold mine," Journal of Applied Geophysics, vol. 36, no. 1, pp. 1-17, 1996.

[21] N. Hosseini, K. Oraee, K. Shahriar, and K. Goshtasbi, "Studying the stress redistribution around the long wall mining panel using passive seismic velocity tomography and geostatistical estimation," Arabian Journal of Geosciences, vol. 6, no. 5, pp. 1407-1416, 2013.

[22] C. Wang, A. Cao, G. Zhu, G. Jing, J. Li, and T. Chen, "Mechanism of rock burst induced by fault slip in an island coal panel and hazard assessment using seismic tomography: a case study from Xuzhuang colliery, Xuzhou, China," Geosciences Journal, vol. 21, no. 3, pp. 469-481, 2017.

[23] H. Benioff, B. Gutenberg, and C. F. Richter, "Crustal strain characteristics derived from earthquake sequences," Transactions, American Geophysical Union, vol. 32, no. 5, pp. 508-514, 1951.

[24] L. Dou, W. Cai, A. Cao, and W. Guo, "Comprehensive early warning of rock burst utilizing microseismic multi-parameter indices," International Journal of Mining Science and Technology, vol. 28, no. 5, pp. 767-774, 2018.

[25] Y. Jiang, H. Wang, S. Xue, Y. Zhao, J. Zhu, and X. Pang, "Assessment and mitigation of coal bump risk during extraction of an island long wall panel," International Journal of Coal Geology, vol. 95, no. 1, pp. 20-33, 2012.

[26] C. Srinivasan, S. K. Arora, and R. K. Yaji, "Use of mining and seismological parameters as premonitors of rock bursts," International Journal of Rock Mechanics and Mining Science \& Geomechanics Abstracts, vol. 34, no. 6, pp. 1001-1008, 1997.

[27] M. He, X. Jia, W. Gong, and L. Faramarzi, "Physical modeling of an underground roadway excavation in vertically stratified rock using infrared thermography," International Journal of Rock Mechanics and Mining Sciences, vol. 47, no. 7, pp. 1212-1221, 2010.

[28] M. A. Meguid, O. Saada, M. A. Nunes, and J. Mattar, "Physical modeling of tunnels in soft ground: a review," Tunnelling and Underground Space Technology, vol. 23, no. 2, pp. 185-198, 2008.

[29] D. D. Jiang, "Experimental study on the relationship between microstructal characteristic and fragment size of rock under dynamic loading," M. S. thesis, University of Science and Technology Liaoning, Anshan, China, 2016.

[30] M. Alber, R. Fritschen, M. Bischoff, and T. Meier, "Rock mechanical investigations of seismic events in a deep long wall coal mine," International Journal of Rock Mechanics and Mining Sciences, vol. 46, no. 2, pp. 408-420, 2009.

[31] J. Kornowski and J. Kurzeja, "Prediction of rock burst probability given seismic energy and factors defined by the expert method of hazard evaluation (MRG)," Acta Geophysica, vol. 60, no. 2, pp. 472-486, 2012.

[32] L. M. Dou and X. Q. He, Theory and Technology of Rock Burst Prevention, China University of Mining and Technology Press, Xuzhou, China, 2001.

[33] W. Cai, L. Dou, Y. Ju, W. Cao, S. Yuan, and G. Si, “A plastic strain-based damage model for heterogeneous coal using cohesion and dilation angle," International Journal of Rock Mechanics and Mining Sciences, vol. 110, pp. 151-160, 2018b. 


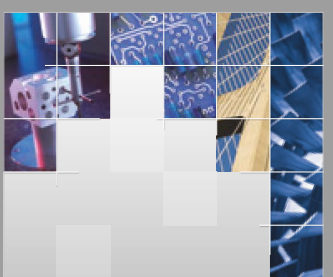

\section{Enfincering}
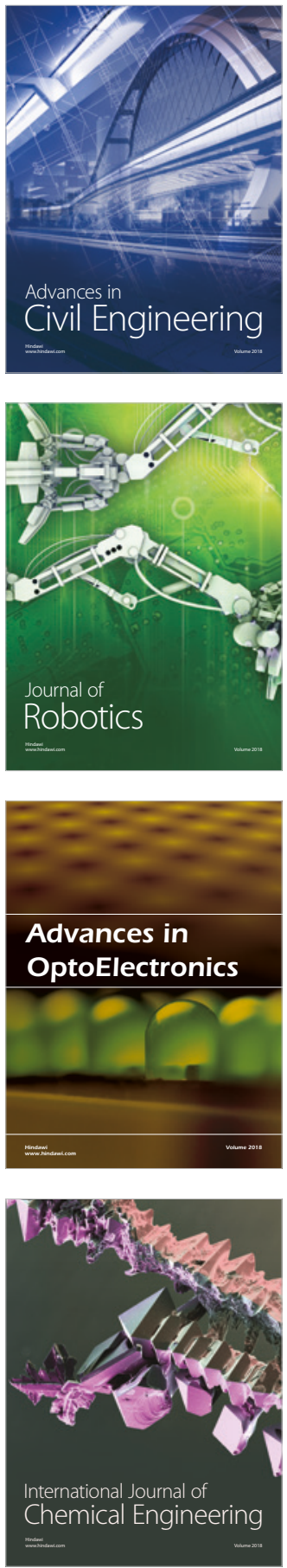

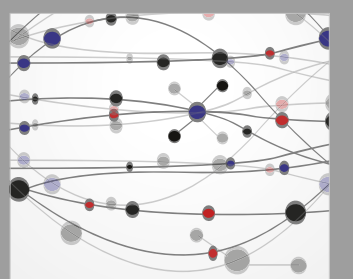

\section{Rotating \\ Machinery}

The Scientific World Journal

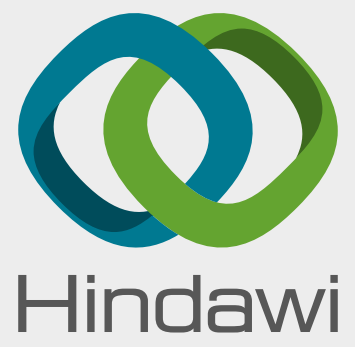

Submit your manuscripts at

www.hindawi.com

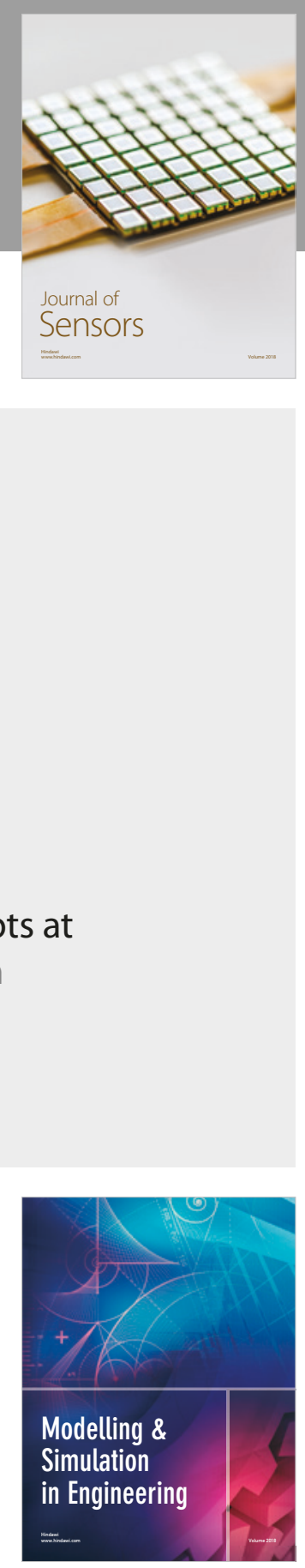

\section{Advances \\ Multimedia}
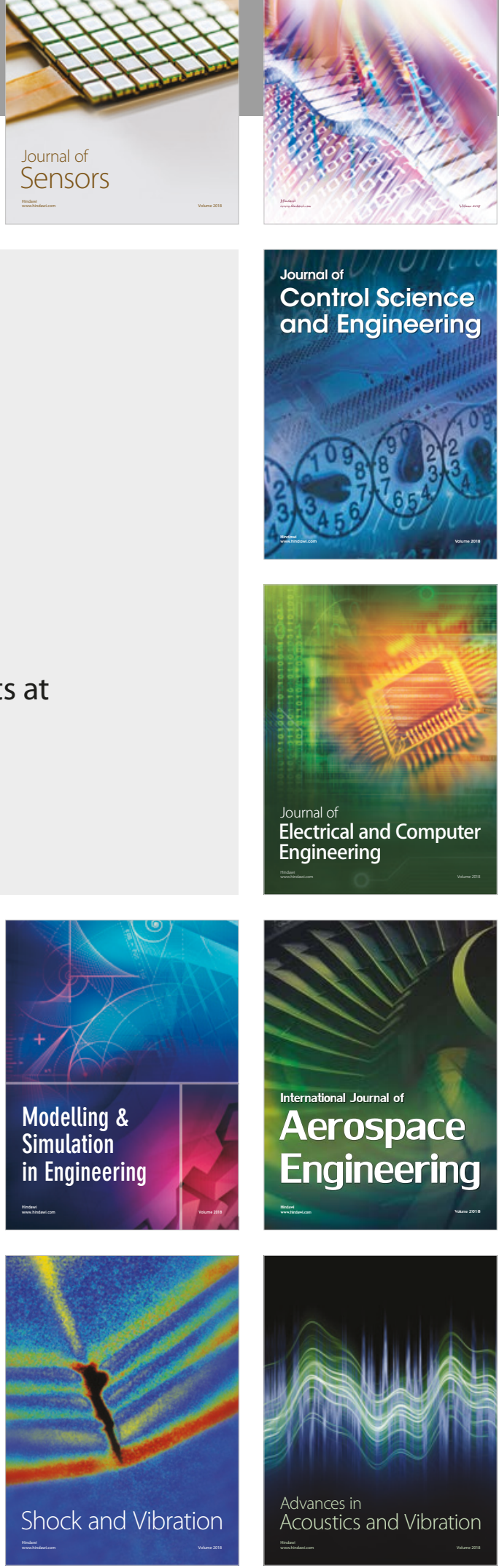